\title{
Santiago
}

Cao

\section{LA “POTENCIA DE NO” COMO RESISTENCIA AL ESTADO DE BIEN-ESTAR COMÚN: LA PERFORMANCE COMO HERRAMIENTA PARA PROPICIAR ENCUENTROS EN LOS ESPACIOS PÚBLICOS}

Tratar de Espacios Públicos es, antes que todo, tratar de dispositivos ${ }^{1}$ de control y gestión de los cuerpos; tanto de las relaciones de los sujetos entre sí como consigo mismos. Micropoderes que allí se activan condicionando los modos de hacer y de relacionarse en ellos. Pero tratar de Espacios Públicos es tratar también de micropolíticas, entendiéndolas como prácticas de resistencias a estos dispositivos, pues será en el encuentro con los otros y sus otros modos de producción de subjetividad que la ciudad se (re)creará de manera no hegemónica.

\footnotetext{
${ }^{1}$ Llamaremos "dispositivo", según lo propuesto por Agamben, a "cualquier cosa que de algún modo tenga la capacidad de capturar, orientar, determinar, interceptar, modelar, controlar y asegurar los gestos, las conductas, las opiniones y los discursos de los seres vivos. No solamente las prisiones, sino además los asilos, el Panoptikon, las escuelas, la confesión, las fábricas, las disciplinas, las medidas jurídicas, etc. cuya articulación con el poder tiene un sentido evidente; pero también el bolígrafo, la escritura, la literatura, (...) y, por qué no, el lenguaje mismo, que tal vez sea el dispositivo más antiguo". Agamben, Giorgio. (2009). O que é contemporâneo? e outros ensaios. Chapecó: Argos, pp. 40-41. (Trad. mía).
} 
Llamaremos por micropoderes a las sutiles manipulaciones del biopoder que, una vez introyectado por los sujetos, se amplificará y manifestará a través de ellos en la repetición de discursos aprendidos. En este sentido, nos referiremos a las prácticas micropolíticas entendiéndolas como los desvíos cotidianos que ejercen los cuerpos; sutiles manifestaciones de aquello que algunos estudiosos de Foucault -diferenciándolas del biopoderdenominaron como biopolítica.
¿Podemos decir que la biopolítica representa un poder que se expresa por la vida misma, no sólo en el trabajo y el lenguaje, sino también en los cuerpos, los afectos, los deseos y la sexualidad? ¿Podemos identificar en la vida el lugar de emergencia de una suerte de contrapoder, de una potencia, una producción de subjetividad que se da como momento de des-sujeción? (...) Se habla de biopoder cuando el Estado ejerce su dominio sobre la vida por medio de sus tecnologías y dispositivos. (...) Para ampliar la aproximación a la definición de biopolítica, podríamos acudir a Deleuze y Guattari, para quienes la biopolítica surge del conjunto del trabajo afectivo, del trabajo de relación, de la flexibilidad temporal y de la movilidad espacial del trabajo $^{2}$.

Regresando a lo planteado en el título del presente Ensayo, a respecto de la potencia de no como resistencia al Estado de Bien-estar Común, es preciso establecer a que llamamos por "resistencia" y por qué esta potencia de no sería una manera de resistir en los espacios públicos. Para ello, comencemos aclarando que al referirnos al "Estado de Bien-estar Común", no lo estaremos haciendo en alusión al Welfare State o Estado de Bienestar Social sino al Estado entendido como soporte y propulsor de las actuales sociedades de consumo. Un Estado que dejó de procurar el bienestar de las personas para -armándose de prácticas urbanísticas hegemónicas- intentar

\footnotetext{
${ }^{2}$ Negri, Antonio. (2004). Guías. Cinco lecciones en torno a Imperio. Barcelona: Paidós, pp.86-88.
} 
condicionar la vida a un "tener que estar Bien" a toda costa y a costa de los muchos que no consiguen encajarse dentro del molde impuesto. Un Estado de la Cultura del Espectáculo-¿o sería más adecuado referirnos a una Espectacularización de la Cultura por parte del Estado?- donde "estar Bien" (Bien bonito, Bien vestido, Bien alegre, Bien sonriente, Bien, Bien, siempre Bien, siempre y todo el tiempo, BIEN) se tornó en una norma a seguir, y donde todo aquello que quede por fuera será catalogado como patológico o criminal. Un "tener que estar Bien" a costa de todo; un Bien-estar sin más que poder estar bien. Un Bien mayúsculo y hegemónico de un Estado que intenta ocultar (o castigar) todo desvío que opaque el brillo de aquello que el estar Bien "tiene que" significar.

Y en un Estado de Bien-estar que se pretende común imponiendo lo Común, tal vez sean dos las figuras que más se le opongan y resistan: la del depresivo y el marginal. En este sentido, la depresión, entendida ya no como una patología sino como síntoma de una sociedad patológica, será "aquello que resiste -al imperativo del gozo, a la fe en la felicidad consumista, a la propia oferta de posibilidades de traición de la vida deseante"3. Si así fuese, ¿podríamos pensar en la depresión como uno de los tantos modos que la fuerza vital encontró para resistir ante la imposición de (Bien) adaptarse a una sociedad que despotencializa la vida? Una resistencia, sí, pero en soledad y sin poder otra cosa más que resistir o morir.

Y en un Estado como este, aquello que precisamente las personas tenemos de común -la posibilidad de ser diferentes los unos de los otros- es reapropiado por el poder hegemónico y devuelto para la población en un discurso de lo Común que se expresa como unión de los "iguales" y expulsión de los “diferentes". Y será en la aplicación práctica de este

\footnotetext{
${ }^{3}$ Kehl, M. R. (2009). O tempo e o cão: a atualidade das depressões. São Paulo: Boitempo, p.103. (Trad. mía)
} 
discurso donde la pretendida ausencia de conflictos podrá ser comprendida como uno de los síntomas patológicos de nuestras sociedades contemporáneas. Sociedades que aprendieron a exigir la aplicación de la llamada pacificación en áreas "conflictivas" de las ciudades; que, en procura de juzgar las diferencias como perniciosas, justifican las suspensiones y violaciones de derechos bajo el pretexto de un Bien-estar Común que falta el respeto a la vida y a los modos otros de vivirla. Y, en una sociedad donde se impone el miedo al otro, volverse "diferente" puede resultar siendo un alto costo a pagar.

¿Serán entonces, la depresión y la marginalidad, dos modos "diferentes" de resistir? Amenazas para un sistema que intentará "demonizarlas" con la intención de aislarlas y controlarlas, transformándolas en estereotipos perniciosos para el Bien-estar Común. Construcciones mediáticas producidas por una industria del miedo que intentará colocar dentro de ellas -como sacos a ser llenados- todo aquello que (de)muestre que también se puede vivir sin tener que estar todo el tiempo "alegre"; que también es posible vivir sin (Bien) adaptarse a los modos ordenados con los cuales se nos pretende organizar la vida en la mayoría de las actuales sociedades de consumo. Y a pesar de tanta construcción mediática, será en la co-existencia cotidiana donde estas dos figuras nos (de)mostrarán que para vivir, para perseverar en la vida, algunas personas precisan no (Bien) adaptarse, negándose con urgencia a permanecer "alegres" o a vivir dentro de las normas organizativas de una sociedad que, siendo atravesada por el miedo, despotencializa la vida. Sociedad que posee un profundo miedo a la tristeza y al tedio. Miedo a no tener tiempo y a tenerlo sin saber qué hacer "con" él. Miedo a saber y a no saber. Miedo a los otros y miedo también de nosotros mismos que a veces nos reconocemos como un otro que se resiste a estar Bien. Miedo, mucho miedo. Si hay algo que caracteriza estas sociedades de consumo, es el miedo. $\mathrm{Y}$ en los espacios públicos, el miedo fue 
instaurándose, tornándolos lugares inseguros en los cuales es mejor no permanecer, no detenernos, no parar para evitar encontrarnos con algún otro que pueda afectarnos. Pues ser asaltados es también ser afectados. Es descubrir que podíamos vivir sin aquella pertenencia. Ser robados puede colocarnos en un lugar en el cual no querríamos estar: en el lugar de las preguntas sin respuestas. Pero encontrarnos con la mirada del otro es también arriesgarse a ser afectados. Y con todo, afortunadamente aún existen "miradas" y "miradas".

En este sentido, si pensamos que los espacios públicos son por excelencia los lugares de encuentro, cabe preguntarnos -tomando por caso, las callesel porqué de la actual tendencia a entenderlos como "espacios entre"; es decir, lugares de paso entre un punto de partida y otro de llegada. ¿Y por qué algunos otros lugares -como es el caso de los parques- dejaron de ser espacios públicos para transformarse gradualmente en "Bienes públicos" a ser protegidos con rejas que impiden su libre uso? ¿Por qué tanto empeño en evitar que las personas nos encontremos? ¿Cuáles son los intereses por detrás de estas (des)construcciones sociales? Pensemos, como posible respuesta a estas cuestiones, que el encuentro -en tanto posibilidad de encontrarnos con otros modos de pensar y hacer (en la) ciudad- es una potencia que abre hacia nuevos rumbos antes no pre-vistos; que desborda los límites impuestos por un biopoder que, en palabras de Foucault, procurará la "administración de los cuerpos y la gestión calculadora de la vida"4. Pero, el encuentro del cual estamos tratando, no es el encuentro de los "iguales" sino de las diferencias; y de cómo aproximarlas sin perderlas. Si nosotros mismos somos des-iguales, ¿por qué tanto empeño en pretender crear una sociedad de iguales? Pues una cosa es intentar que todas las personas que habitan la ciudad tengan acceso a los mismos derechos civiles,

${ }^{4}$ Foucault, Michel. (1998). Historia de la sexualidad I. La voluntad de saber. Madrid: Siglo XXI, p.169. 
y otra, distinta, es pretender anular sus diferencias, las cuales generan diferentes necesidades y modos de vivir junto-con en las ciudades. Y para poder comprender que hay otras necesidades diferentes de las mías, preciso confrontarme con aquellos otros que las poseen. Y si en ese encuentro se genera un conflicto, ¡bienvenido sea! Pues si consiguiésemos entender que estos conflictos tendrán su origen dentro del campo de saberes de cada uno, en vez de intentar calmar las diferencias, podríamos dejar esta herida abierta para intentar ver a través de este otro, cuales otros modos de vivir podríamos incorporar en nuestro cotidiano.

En los conflictos, las tensiones serán las señales que evidenciarán que, a pesar del biopoder intentar fijarnos en una identidad única e identificable, algo que creíamos firme está moviéndose; algo que estaba endureciéndose, vuelve al movimiento. Y el movimiento, aunque "doloroso", es una característica propia de la vida. O como dijera el célebre personaje de Cervantes, Don Quijote de La Mancha, en la versión cinematográfica de Orson Wells (1992), "ladran, Sancho, señal que cabalgamos":

Pero, cuando (Bien) adaptarse excluye la posibilidad de procurar otros modos de interactuar, cuando no podemos más que «poder sí», una manera de resistir y recuperar nuestra potencia en una sociedad que despotencializa la vida, es intentar regresar al estado anterior al acto, al estado de indiscernibilidad entre el "si" y el "no" desde el cual recuperar la potencia de no.

\section{La "potencia de no" como un primer momento de la resistencia}

Antes de continuar avanzando, pensemos primero a respecto de aquello que "Aristóteles llama dýnamis, potencia (un término que, es bueno recordar, 
significa tanto potencia como posibilidad)" ${ }^{\prime \prime}$, y que, por lo tanto, es anterior al acto. No estamos refiriéndonos en este momento a la potencia de actuar en relación a la Teoría de los Afectos propuesta por Baruch Spinoza ${ }^{6}$-más adelante volveremos a él- sino a la potencia del pensamiento, en la cual según Aristóteles- aquello que está en potencia no está en acto. En este sentido, entenderemos que "la impotencia [adynamía] (...) es una privación contraria a la potencia [dynámei]. Toda potencia es impotencia de lo mismo y con respecto a lo mismo", . Pero tenemos que comprender que esta adynamía, "no significa aquí ausencia de toda potencia, sino potencia de no (pasar al acto) ${ }^{\prime 8}$. Será precisamente esta potencia de si y potencia de noconstituyentes de toda potencia humana - lo que diferenciará a los hombres de los demás seres vivos.

¿Que será, entonces, lo que resolverá que se pase de la potencia al acto? Agamben, a respecto de esto, opinó que "creer que la voluntad tiene algún poder sobre la potencia, que el paso al acto es el resultado de una decisión que acaba con la ambigüedad de la potencia (...), tal es justamente la perpetua ilusión de la moral"9. Si no es la voluntad lo que resolverá que se pase de la potencia al acto, ¿cómo continuar afirmando -como comúnmente se dice- que "querer es poder? ¿Hay algún lugar, entre la potencia y el acto, donde alojar este "querer"? Y si en vez de "querer", nos refiriésemos a “desear”, ¿habría algún lugar, entre la potencia y el acto, para el deseo? Pero entendamos este deseo, no como el Psicoanálisis Lacaniano lo entendió, es

\footnotetext{
5 Agamben, G. (2007). La potencia del pensamiento, en La potencia del pensamiento: ensayos y conferencias. Buenos Aires: Adriana Hidalgo, p.354.

${ }^{6}$ Entendemos por Afecto, según lo propuesto por Spinoza, a "las afecciones del cuerpo, con las que se aumenta o disminuye, ayuda o estorba la potencia de actuar". Spinoza, Baruch (2000). Ética demostrada según el orden geométrico. Madrid: Trotta, P. III, Def. 3.

7 Agamben, Ibid, p.361.

8 Idem.

${ }^{9}$ Agamben, G. (2011a). Bartleby o de la contingencia, en Preferiría no hacerlo. Valencia: Pre-Textos, pp.111-112.
} 
decir, no en el sentido de una falta como motor del deseo ${ }^{10}$, sino -en una línea de pensamiento más próxima a Deleuze y Guattari- el deseo como una potencia que desborda y que me impulsará a accionar.

\begin{abstract}
Por una parte ya lo tenéis, no experimentáis un deseo sin que él no esté ya presente, sin que no se trace al mismo tiempo que vuestro deseo; pero por otra no lo tenéis, y no desearéis si no lográis construirlo, si no sabéis hacerlo, encontrando vuestras posiciones, vuestros agenciamientos, vuestras partículas y vuestros flujos. (...) Deseo: ¿quién, salvo los Curas, se atrevería a llamar «carencia» a eso? Nietzsche lo llamaba Voluntad de poder. ${ }^{11}$
\end{abstract}

En este sentido, entenderemos que el deseo no será ni falta, ni producción individual, pues, "como todo agenciamiento es colectivo, él mismo es un colectivo" $"$. El deseo será tejido junto-con un otro y precisaremos de esos otros para poder tejerlo en mutua co-afectación. Ahora, la pregunta es, ¿cuál es la relación entre desear y poder accionar este deseo? Siendo potencia que desborda tornándose acto - por lo tanto, anterior al mismo- y si, según lo propuesto, en la actualidad del vivir en las ciudades, la potencia de no se encontraría -sino inhibida, por lo menos- disminuida, ¿este deseo será un deseo potente? Pues, según lo que estamos proponiendo, si fuese anterior al acto, tendríamos que tener la posibilidad de desear poder-no accionar para que esta acción se resuelva potentemente. Pero si a nivel del pensamiento este poder-no estuviera siendo excluido, reduciéndose el campo de lo posible a una única elección en la cual no pueda más que desear poder -o dicho de otro modo, no pueda desear poder-no-, nuestros actos estarían siendo actos que carecen de potencia en su origen. Y si esto fuera así, ¿qué

\footnotetext{
10 "Nunca, en nuestra experiencia concreta de la teoría analítica, podemos prescindir de una noción de la falta del objeto como central. No es negativa, sino el propio motor de la relación del sujeto con el mundo". Lacan, Jacques (1995). O seminário - livro 4: a relação de objeto (1956-1957). Rio de Janeiro: Jorge Zahar, p. 35. (Trad. mía)

${ }^{11}$ Deleuze, Gilles; Parnet, Clair (1980). Diálogos. Valencia: Pre-Textos, pp.103.

${ }^{12}$ Ibid, p.109.
} 
está sucediendo con nuestro poder-no-poder en las actuales sociedades de consumo? Al respecto de esto, podemos pensar, según lo propuesto por Agamben, que "nuestra tradición ética ha tratado a menudo de soslayar el problema de la potencia reduciéndolo a los términos de la voluntad y de la necesidad: su tema dominante no es lo que se puede, sino lo que se quiere o lo que se debe" ${ }^{\not 13}$. En este sentido, ¿cuáles producciones de deseo y cuales devenir-deberes están conformando nuestro imaginario? ¿Y cuáles dispositivos están siendo activados para, limitándolo, disminuir nuestra fuerza vital?

Para los debidos fines, podríamos pensar en una distinción entre deseos y mandatos, asociando estos últimos a los dispositivos despotencializadores de la vida, y entendiendo los deseos como aquellas fuerzas que la potenciarán.

Si pensamos, a partir de esta distinción, que el imaginario social condicionado por los mandatos del "deber-querer"- condicionará por su parte a la potencia del pensamiento, limitando la potencia de actuar a un "yo debo-yo quiero", no habría en este paso al acto una libertad de acción. Por lo menos si en este "deber-querer" se excluye la posibilidad de poder-no (deber-querer) actuar. Por lo tanto, no habría, como consecuencia de esto, una acción potente puesto que en su origen -a nivel del pensamientoestaría faltando la potencia de no como alternativa a la potencia de sí.

En este sentido, pensando en la noción de biopoder desarrollada por Foucault, donde "el viejo derecho de hacer morir o dejar vivir fue remplazado por el poder de hacer vivir o de rechazar hacia la muerte"14, propondremos que en la actualidad, este biopoder se caracterizará, también, por hacer-decir y dejar-pensar, entendiendo este "dejar-pensar" como un

\footnotetext{
${ }^{13}$ Agamben, Ibid, p.111.

${ }^{14}$ Foucault, op. cit., p.83.
} 
poder pensar dentro de lo posible de ser pensado. Mejor dicho, dentro de aquello dado como posible, en un repertorio de pensamiento acotado en su potencia de no. De esta manera, el biopoder, operando a nivel cognitivo, afectará la potencia de actuar de los cuerpos, inhibiéndose así la posibilidad de actuar libremente.

Por este motivo, en nuestras sociedades actuales, donde el biopoder "ya no se incumbe de hacer vivir, ni de hacer morir, sino de hacer sobrevivir" 15 creando sobrevivientes, tenemos que buscar la causa de la disminución de su potencia de actuar en la pérdida o en la imposibilidad de desarrollar su potencia de no. O dicho de otro modo, si la potencia del pensamiento fue restringida en su potencialidad, ¿se tornó ella impotente? ¿Y de un pensamiento impotente, puede generarse algo más que actos impotentes?

Pensemos, en esta línea, que todo mandato supone un Soberano que lo dictó $\mathrm{y}$ ante el cual tenemos que responder por nuestros actos. Mandatos que organizan la vida en patrones correctos y correctos modos de vivir en sociedad bajo el citado pretexto del llamado "Bien-estar Común". Contrato social cuya violación acarreará un riesgo punitivo. Y siendo el miedo a su incumplimiento lo que se encuentra por detrás, todo mandato perseverará en una despotencialización de la vida puesto que en vez de expandirla, la contraerá. Todo mandato, siendo deuda pasada, frenará la capacidad creativa de la vida, limitando la potencia poiética a las márgenes de lo necesario y a la posibilidad única de una sombra única producida por una única fuente de conocimientos. Por el contrario, el deseo será aquello que me impulsará, que desbordará los límites impuestos y, siendo potencia creativa, todo deseo será afirmación de vida y toda voluntad en libertad perseverará en el vivir. Desear es poner en acto la potencia de la vida que se

${ }^{15}$ Pelbart, Peter Pál (2013). O avesso do niilismo: cartografias do esgotamento. São Paulo: N-1 Edições, p.26. (Trad. mía) 
resiste -aun arriesgando la propia vida - a ser limitada en sus posibilidades de desarrollo. Si es la vida la que se afirma a través del deseo, será el miedo a perderla lo que se oculte detrás de los mandatos y del Soberano. Un temor que, según lo propuesto por Hobbes ${ }^{16}$, nos habría llevado a resignar una porción de nuestra libertad. Pero, resignándola, resignamos también nuestra posibilidad de desear libremente, resignando con ello nuestra potencia creativa en tanto cuerpos productores de subjetividades que somos.

Lo que (entre) veo como tendencia en los actuales modos de vivir y transitar en los espacios públicos, lejos de tratarse del paso de una potencia al acto, se asemeja más a una (re)escritura de un saber dominante que, en la acción, imprime nuevamente sus modos únicos y correctos de vivir. Si esto fuera así, pasar al acto atravesados por los mandatos sociales del Bien-estar Común, estaría tratándose del hacer impotente de una vida despotencializada. El mandato, siendo deuda que inhibe la potencia creativa, intentará cercarnos en una (re)escritura de lo necesario, pero, como alternativa al mismo, el deseo nos impulsará a procurar nuevas escrituras que incluirán lo posible dentro del repertorio del pensamiento.

Y si resistir fuese una tentativa para recuperar la potencia de la vida... ¿podemos hacer otra cosa más que resistir?

\section{Los encuentros como resistencias cuerpo-a-cuerpo}

Según lo observó Bárbara Stiegler, "para Nietzsche todo sujeto vivo es primeramente un sujeto afectado, un cuerpo que sufre de sus afecciones, de

\footnotetext{
${ }^{16}$ Véase al respecto Hobbes, Thomas (2003). Leviatã ou Matéria, Forma e Poder de um Estado Eclesiástico e Civil. São Paulo: Martins Fontes.
} 
sus encuentros, de la alteridad que incide en él, de la multitud de estímulos y excitaciones que le corresponde seleccionar, evitar, escoger, recibir" ${ }^{17}$.

Y si el encuentro es una potencia, ¿qué está sucediendo con la potencia de los encuentros en los espacios públicos? ¿Habremos perdido el interés de (re)conocer al otro, de darle existencia? O, tal vez, estemos perdiendo el deseo de ser vistos por los otros, de existir de una otra manera, diferente de la aprendida; de arriesgarnos a las múltiples posibilidades de una vida que no sea la vida de vitrina que se nos "ofrece" a través de los Medios Masivos de Comunicación. En síntesis, de resistirnos a la sobrevida impuesta en las actuales sociedades de consumo.

Pudiendo accionar tanto una (re)escritura como una escritura, lo que está aquí en juego no es la voluntad sino los saberes previos a ella. Pero, si como propusimos anteriormente, todo deseo es afirmación de vida, y la vida, en tanto potencia creadora, es actualización contigua, el deseo tendrá la fuerza para actualizar los saberes aprendidos, expandiendo los horizontes de posibilidades, expandiendo de esta manera la propia vida.

Y si, según lo dicho anteriormente, el miedo despotencializa la vida, no sería el camino de los mandatos ni del Soberano el que transitaríamos si nuestro deseo fuese potenciarla. Si desear es perseverar en la vida, procuraríamos regresar a los espacios públicos en tanto lugares de encuentro con los otros, y, en asociación con estos otros, podríamos producir bienestar(es), entendiéndolos como estados de libertad donde (también) podamos pasar al acto atravesados por el deseo. Libertad para producir subjetividades otras sin ser castigados por ello; contaminando y siendo contaminados por los otros y sus otras producciones de realidad. Expandiéndonos en las múltiples y diversas maneras de vivir en sociedad. Y

\footnotetext{
${ }^{17}$ Apud Pelbart, op. cit., p.31. (Trad. mía)
} 
en este punto, Spinoza se nos ofrece como una alternativa al pensamiento de Hobbes, pues, ya no delegaré mi libertad en un Soberano por miedo a perder la vida, sino que, precisamente por tener libertad, es que podré asociarme con otras personas para potenciarla.

\section{Resistir y Re-Existir: los encuentros como producción no hegemónica de sociedad}

Si en un comienzo dijimos que tanto el depresivo como el marginal podrían ser dos figuras contemporáneas que se resisten a (Bien) adaptarse al Estado de Bien-estar Común, será preciso aclarar ahora que ni el depresivo es un rebelde ni todo marginal un "Robin Hood", pues, lo que falta en ellos, es la voluntad de resistir, la cual tornaría el acto de resistencia en un acto político y colectivo, y no en una resistencia en soledad. "Durante milenios, el hombre siguió siendo lo que era para Aristóteles: un animal viviente y además capaz de una existencia política; el hombre moderno es un animal en cuya política está puesta en entredicho su vida de ser viviente." 18

Si es la vida la que está en cuestión, ¿podemos otra cosa más que resistir? Y si no toda resistencia es un acto político, ¿cómo hacer para recuperar nuestra existencia política en una sociedad que intenta reducirnos a meros sobrevivientes? "Permanezcamos por ahora en ese postulado inusitado que Agamben encuentra en el biopoder contemporáneo: hacer sobrevivir (...) la vida humana reducida a su mínimo biológico" ${ }^{19}$.

Si el biopoder hace sobrevivir en una sobrevida impotente, será necesario anteponer a esta condición una otra posibilidad: la resistencia. Pero, ¿cómo

\footnotetext{
${ }^{18}$ Foucault, op. cit., p.85.

${ }^{19}$ Pelbart, op. cit., p.26.
} 
pensar en resistencias que, más allá de oponerse a la sobrevida impuesta por el biopoder, puedan también proponerse junto-con otros, en la búsqueda de otros modos potentes de vivir en sociedad?

Llegado en este punto, podríamos pensar que quizá no sea la palabra "resistencia" la más adecuada para lo que estamos proponiendo. Por lo menos, no si la entendemos desde el punto de vista de la física clásica, que la considera como la fuerza que ejercerá un cuerpo contra cualquier otro que intente desplazarlo de su espacio. ¿Si tanto hemos insistido al respecto del accionar junto-con, porque proponer una resistencia frente a las actuales prácticas del Estado de Bien-estar Común, siendo que esa palabra conlleva la idea de accionar contra otro? Propongamos entonces otra palabra: reexistencia. Y entendiéndola como la posibilidad de existir en modos otros de existencia, sugeriremos que la misma sólo podrá darse si es junto-con un otro, pues los modos otros, posibles, serán los modos de los otros. Y si un cuerpo tiene como posibilidad el poder afectar otro cuerpo aumentando su potencia, propondremos entender la re-existencia como un acontecimiento en el cual no sólo soy afectado sino que también afecto, dándonos de manera simultánea la alternativa de una otra y posible existencia en una acción conjunta e inseparable de (re)conocimiento.

Para dilucidar esta cuestión, pensemos en la producción del Imaginario como un "pensar con imágenes". Imágenes que, a modo de un espejo, nos reflejarán en una construcción de existencia conjunta. Para ello es preciso que entendamos esta metáfora ya no desde el Estadio del Espejo propuesto por $\operatorname{Lacan}^{20}$ en donde el sujeto comenzará a identificar su imagen diferenciándose del otro, y donde, paradójicamente, para poder diferenciarse tendrá primero que alienarse (ya que lo designado como "Yo" irá formándose a través de ese otro, esto es, mediante una imagen que -como

\footnotetext{
${ }^{20}$ Véase al respecto Lacan, J. (2005). Escritos I. Buenos Aires: Siglo XXI.
} 
en un espejo- le dará el otro). Propongamos, entonces, que nos vemos junto-con los otros que nos reflejan, y que, en ese sentido, no habrá posibilidad de ser reflejados si no estamos frente a ellos. Es decir, ya no un reflejo primero, un Sujeto a ser constituido por el otro, sino una acción conjunta y simultánea de ver y ser visto; una producción de existencia que se dará junto-con y para un otro. Existencia móvil, dinámica, y en contigua trans(forma)acción, pues cada uno de estos otros me verá de una manera diferente. Y como cada uno de estos otros, por su parte, se ha visto juntocon otros, mi mirada sobre mí y sobre el mundo será una mirada de multitudes. Y, precisamente, será en el encuentro donde voy a poder encontrarme en modos otros de vivir, ya no necesarios, sino posibles. Los otros - con sus otros otros - serán quienes me posibilitarán dejar de ser para poder estar, transitando un estado contiguo. Pero un estado con "e" minúscula. O mejor dicho, una pluralidad de "e" minúsculas, que resisten y posibilitan re-existir, que fugan de la continua tentativa de ser atrapados por un aparato de Estado ${ }^{21}$ que procurará identificar y fijar cada ser viviente en un Ser continuo, lineal y único.

\section{Cuanto más ha perdido el ciudadano metropolitano la intimidad con los otros, cuanto más incapaz se ha vuelto de mirar a sus semejantes a los ojos, tanto más consoladora es la intimidad virtual con el dispositivo, que ha aprendido a escrutar su retina tan en profundidad. Cuanto más ha perdido toda identidad y toda pertenencia real, tanto más gratificante es ser reconocido por la Gran Máquina. ${ }^{22}$}

Si no somos únicamente vistos; si también vemos, y al ver, le damos existencia al otro, ¿tendría sentido pensar en resistencias y re-existencias sin los encuentros cuerpo-a-cuerpo con estos otros?

\footnotetext{
${ }^{21} \mathrm{Al}$ respecto del concepto de "aparato de Estado", véase Deleuze, Gilles \& Guattari, Félix (2004). Tratado de Nomadología: la Máquina de Guerra, en Mil Mesetas: Capitalismo y Esquizofrenia. Valencia: Pre-Textos.

${ }^{22}$ Agamben, G. (2011b). Identidad sin Persona, en Desnudez. Buenos Aires: Adriana Hidalgo, p.77.
} 
Si imaginar fuese pensar con imágenes, y si la realidad fuese cosa de todos y por todos producida, ¿tendría sentido pensarla -imagéticamente- como cosa de pocos y siendo construida -mediáticamente- por pocos?

En tiempos en los cuales, los canales de comunicación han sido transformados en medios de (in)formación, y donde la tecnología dejó de ser un medio para convertirse en un filtro (inter)mediario entre las personas, el encontrarse se vuelve tan necesario como respirar. Por lo menos, si más allá de llenar los pulmones con aire insípido, queremos disfrutar de la rica multiplicidad de aromas que el mundo ofrece a quienes se dispongan a recorrerlo.

\section{El rostro como línea de fuga}

Si pensamos que los sujetos - según lo propuesto por Agamben ${ }^{23}$ - son fruto del encuentro entre los dispositivos y los seres vivientes, produciéndose subjetivaciones como resultados de estos encuentros, los espacios públicos serán algunos de los lugares donde los límites quedarán evidenciados. Limites que, generados por los dispositivos, condicionarán la vida de los vivientes bajo la forma de permisos, consensos y prohibiciones. Siendo así, podríamos pensar en ciertas prácticas artísticas -como algunas Intervenciones Urbanas y Performance en espacios públicos- a fin de emplearlas como instrumentos para alterar estas subjetivaciones. Tácticas para propiciar otros encuentros que contaminen los imaginarios de las personas, reverberando en otras producciones no hegemónicas de ciudad. Y si, como dijimos anteriormente, al (re)conocer al otro no sólo le vemos como también le damos existencia, en estas intervenciones serán estos otros

${ }^{23}$ Agamben (2009), op.cit. 
quienes también, al (re)conocernos, nos contaminarán con sus otros modos de existencia posibles.

Pero, en esta exposición pública, existe el riesgo de ser reconocidos (también) por los dispositivos de identificación de personas y no sólo por las personas mismas. Y escojo intencionalmente esta palabra, "persona", por derivar etimológicamente del verbo en latín «personare», que significa "sonar a través de". Como en el teatro de la antigua Grecia, donde los actores utilizaban máscaras para presentarse, y donde su voz sonaba a través de ellas. Pero nuestras máscaras contemporáneas, en tanto personas que somos, serán nuestros propios rostros, (con)formados por los tantos otros y sus otros que les (con)formaron, y que (re)sonarán a través de -y junto-con- ellos a la hora de mirarnos. El rostro es aquello que está en contiguo movimiento, que no se deja atrapar en la tentativa de identificarlo.

Cada vez que me veo en el espejo me sorprendo de la imagen allí reflejada, pues la imagen que tengo internalizada es siempre otra; siempre diferente. Una imagen compuesta por las palabras introyectadas y no sólo por las fotos que me recuerdan que tengo una cara. Pues "cara" y "rostro" son cosas diferentes. Y el rostro -al igual que las palabras (aún) no capturadas por la escritura- se transforma todo el tiempo en mi memoria. Así, al verme en el espejo, me sorprendo de no encontrar(me) con aquellas imágenes fijas de las fotos. Imágenes sin tiempo ni movimiento, que contrastan con el tiempo que fuga y con el rostro que me hace fugar de la tentativa de querer-Ser un Yo único e indivisible; un individuo.

Frente al espejo, me pregunto, “¿Quién es él? ¿Por qué no te reconozco? ¿Por qué, cada vez que intento ver-me, te presentas ocupando mi lugar en el reflejo?”. El rostro fuga de mi propio intento de identificar-lo, de identificarme, poniéndome a salvo de una parte de mí mismo que aprendió a decir "Yo Soy", o "Soy Yo". El rostro me (de)muestra que no soy un Yo, que somos 
(nos)otros; una multitud inidentificable, pues, “¿si yo soy vos, vos quién soy?". El rostro es la pregunta sin respuesta que nos moviliza. Tal vez por ello haya tanto empeño en cubrir el rostro con una cara. Una "face" que (im)porta los valores de una sociedad que nos impone (im)portarla a costa de negar el resto del cuerpo. O mejor dicho, los restos del cuerpo. La piel estirada, brillante, de las "faces cirugiadas", contrasta con las opacas, obscuras arrugas del cuello, de las manos, de los pies, que reclaman por su derecho a tener edad, memoria, finitud.

\section{La Performance en los espacios públicos como un Cuerpo sin Rostro $(C s R)$}

En la procura de propiciar encuentros en los espacios públicos, con la intención de generar imaginarios otros que subviertan los mandatos del Bien-estar Común, la Performance puede resultar siendo una instrumetno interesante a la hora de producir discontinuidades en los discursos hegemónicos. Espacios entre por donde fugar en medio del ritmo cotidiano de una sobrevida saturada de distracciones y espectáculos; resistencias dentro de un modelo social estructuralmente jerárquico y opresivo para con las diferentes formas de vida.

Y si imaginar es pensar con imágenes, será entonces necesario pensar -al menos un poco- con imágenes no tan conocidas. Empleando la Performance en espacios públicos, podemos potenciar un pensamiento nómade en medio de una sociedad que pretende estable-ser-se. Para ello, tenemos que generar propuestas que, observadas rápidamente, posean una forma aparente lo suficientemente parecida con los saberes hegemónicos a fin de activarlos; pero, al mismo tiempo, lo suficientemente diferenciadas de aquellos para -al ser vistas con mayor detenimiento-generar un extrañamiento en los sujetos. 
Extrañamiento que interrumpa su caminar, que les provoque detenerse, y con ello, encontrarse con otras personas que también han detenido su caminar.

Pero, si los dispositivos de identificación de personas intentan capturar los rostros atrapándolos en caras reconocibles, y si para el biopoder, identificar al otro con la intención de "definir al enemigo se convierte en una cuestión de máxima importancia" 24 , portar una "cara" durante una Performance en espacios públicos, puede resultar siendo un alto costo a pagar.

Siendo así, ¿cómo propiciar prácticas de re-existencia que dificulten la producción de identidades fijas, sin ser capturados en el intento?

Propongo entonces que pensemos la Performance en espacios públicos como un Cuerpo sin Rosto (CsR) que tenga como posibilidad el ser depositario de múltiples rostros en contiguo desplazamiento frente a los saVeres de las personas que la observan. La Performance entendida como una herramienta para desorganizar el Cuerpo social a partir de sus propios saberes. Y el artista, liberado ya de tener que ser (re)conocido como tal al momento de accionar.

(...) "mis ojos ya no sirven para nada, pues sólo me remiten la imagen de lo conocido. La totalidad de mi cuerpo debe devenir rayo perpetuo de luz, moviéndose a una velocidad cada vez mayor, sin respiro, sin retorno, sin debilidad (...). Sello, pues, mis oídos, mis ojos, mis labios”. CsO. Sí, el rostro tiene un gran futuro, a condición de que sea destruido, deshecho. ${ }^{25}$

Concluyendo, propondremos que si la potencia del pensamiento es inhibida, se inhibirá también la potencia de actuar, dificultándose la posibilidad de relacionarnos y, con esto, de producir sociedad. Pues, pasar al acto junto-

\footnotetext{
${ }^{24}$ Negri. Op. cit., p. 150.

${ }^{25}$ Deleuze, G. \& Guattari, F. Op. cit., p.177.
} 
con un otro, para otro, frente a otro, es crear sociedad; pero para ello precisamos mantener porosa nuestra capacidad de afectar y de ser afectados, sin la cual no habrá posibilidad alguna de resistir al biopoder.

Y si actuar no sólo es una acción contra, sino también junto-con otro, será preciso pensar tanto en la posibilidad de resistencias como también en reexistencias, entendiendo que re-existir es poder pasar al acto aquello que estaba en potencia, expandiéndose la vida en los modos múltiples de vivirla.

Ahora, la pregunta es, ¿cómo resistir sin que seamos castigados por ello? ¿Y cómo re-existir sin perecer en la tentativa? Pues, como propuso Negri, "también el kamikaze es un cuerpo que resiste. Nuestro problema no es, evidentemente, el del kamikaze, nosotros queremos ejercer una resistencia que sea al mismo tiempo afirmación de deseo y de vida." 26

\footnotetext{
${ }^{26}$ Negri. Op. cit., p.154.
} 


\section{REFERENCIAS}

Agamben, Giorgio (2007). La potencia del pensamiento, en La potencia del pensamiento: ensayos y conferencias. Buenos Aires: Adriana Hidalgo.

(2009). O que é contemporâneo? e outros ensaios. Chapecó: Argos.

(2011a). Bartleby o de la contingencia, en Preferiría no hacerlo. Valencia: Pre-Textos. (2011b). Desnudez. Buenos Aires: Adriana Hidalgo.

Deleuze, Gilles; Guattari, Félix (2004). Mil Mesetas: Capitalismo y Esquizofrenia. Valencia: Pre-Textos.

Deleuze, Gilles; Parnet, Clair (1980). Diálogos. Valencia: Pre-Textos.

Foucault, Michel (1998). Historia de la sexualidad I. La voluntad de saber. Madrid: Siglo XXI.

Hobbes, Thomas (2003). Leviatã ou Matéria, Forma e Poder de um Estado Eclesiástico e Civil. São Paulo: Martins Fontes.

Kehl, Maria Rita (2009). O tempo e o cão: a atualidade das depressões. São Paulo: Boitempo.

Lacan, Jacques (1995). O seminário - livro 4: a relação de objeto (19561957). Rio de Janeiro: Jorge Zahar. (2005). Escritos I. Buenos Aires: Siglo XXI. 
Negri, Antonio (2004). Guías. Cinco lecciones en torno a Imperio. Barcelona: Paidós.

Pelbart, Peter Pál (2013). O avesso do niilismo: cartografias do esgotamento. São Paulo: N-1 Edições.

Spinoza, Baruch. (2000). Ética demostrada según el orden geométrico. Madrid: Trotta. 